\title{
The activity of gastric ghrelin positive cells in obese patients treated surgically
}

\author{
Jacek Dadan', Hady Razak Hady'1, Robert Lukasz Zbucki ${ }^{1,2}$, Paweł Iwacewicz'1, \\ Artur Bossowski ${ }^{3}$, Irena Kasacka ${ }^{4}$
}

\begin{abstract}
${ }^{1} 1^{\text {st }}$ Department of General and Endocrinological Surgery, ${ }^{2}$ Department of General and Experimental Pathology, ${ }^{3}$ Second Department of Children's Diseases, ${ }^{4}$ Department of Histology and Embryology, Medical University of Białystok, Białystok, Poland
\end{abstract}

\begin{abstract}
Ghrelin is a 28 amino acid peptide hormone regulating food intake and stimulating releasement of growth hormone. It is produced in a distinct endocrine call known as X/A - like cells. The most abundant source of this very important factor in energy homeostasis is gastric fundus. Regulatory mechanisms of ghrelin synthesis and secretion in physiological and pathological states are not discovered completely. The aim of our study was evaluation of the activity of gastric $\mathrm{X} / \mathrm{A}$-like cells in obese patients before and after the most popular surgical bariatric procedures - Roux - Y Gastric Bypass (RYGB) and Laparoscopic Adjustable Gastric Banding (LAGB). Obese patients in number 18 took part in the study. LAGB was performed in 7 patients and RYGB in 11 patients. Peripheral blood was taken from each patient before operation and first day, seventh day, one month and three months after surgery. Ghrelin level was determined by RIA technique. The specimen of stomach was taken from circular stapler after gastrojejunostomy during RYGB and immunohistochemical study of gastric mucosa, using the EnVision method and specific monoclonal antybodies against ghrelin was performed. The intensity of ghrelin-immunoreactivity in X/A-like cells was analyzed using Olympus Cell D image analysis system. Efficiency of bariatric procedures was estimated by EWL- excess weight loss. We observed very strong immunohistochemical reactions of gastric X/A-like cells, accompanied by lower ghrelin plasma concentration, in comparison to the control group. LAGB procedure induced increase of ghrelin plasma level while RYGB procedure induced decrease of this hormone. The main finding of the present study is the hypoactivity of gastric X/A-like cells in obese patients in comparison to the control group.
\end{abstract}

Key words: ghrelin, X/A-like cells, obesity, bariatric surgery

\section{Introduction}

Ghrelin is a peptide hormone regulating food intake and stimulating releasement of growth hormone $(\mathrm{GH})$. It was discovered in 1999 by Kojima et al [1]. The purification of ghrelin was performed by screening several tissues and high amount of this hormone was found in stomach extracts [2]. The discovery of ghrelin was rooted in the search for an endogenous ligand for the growth hormone secretagogue receptor (GHS $\mathrm{R})$ [1]. The word ghrelin originally comes from word ghre which means in Proto-Indo-European language "grow" [3].

Correspondence: J. Dadan, $1^{\text {st }}$ Department of General and Endocrinological Surgery, Medical University of Białystok, M. Skłodowskiej-Curie 24a, 15-276 Białystok, Poland; tel. (+4885) 7468620, e-mail: klchirog@amb.edu.pl
The main organ that produces ghrelin is stomach and immunohistochemical analysis has indicated that it is produced in a distinct endocrine call known as $\mathrm{X} / \mathrm{A}$ - like cells distributed in the mucosal layer of stomach $[4,5]$. These cells contain round, compact, electron - dense granules. The most abundant source of ghrelin synthesis is gastric fundus which produces ten times more of the hormone than the duodenum $[4,6,7]$. The cells secreting ghrelin are also present in the small and large bowel [4]. Most of X/A - like cells are "closed", what means that they do not directly contact the gastric lumen $[4,8]$. Minor amounts of ghrelin are produced in the lungs, pancreatic islets, gonads, adrenal cortex, placenta and brain [9]. In the central nervous system ghrelin neuronal cells were identified in the hypothalamic arcuate nucleus what is the region of appetite control [3]. The concentration of ghrelin in human blood samples is $100-120 \mathrm{fmol} / \mathrm{ml}$ [10]. 
Ghrelin is a 28 amino acid peptide with an essential $\mathrm{n}$ - octanoyl modified by an acyl acid [11]. The human ghrelin gene is localized on chromosome 3 (3p 25-26), contains 4 exons and 3 introns [11].

The main regulator of plasma ghrelin level is food intake [11,12]. Plasma ghrelin level is increased during starvation and decreased after meals [11]. Oral or intravenous administration of glucose decreases plasma ghrelin concentration [13]. Plasma ghrelin level is low in obese people and high in lean people [11]. People suffering from anorexia nervosa have highly increased levels of plasma ghrelin [14].

Ghrelin is a very important factor in energy homeostasis, a strong orexigenic and adipogenic molecule [11]. Administration of this hormone stimulates appetite, food intake and promotes weight gain [15]. Circulating ghrelin levels decrease with feeding and increase before meals [15]. This protein stimulates appetite through the hypothalamic arcuate nucleus [14]. The arcuate nucleus is also the target site of leptin, an appetite - suppressing hormone from adipose tissues [15].

Circulating ghrelin activate neurons expressing neuropeptide Y (NPY) and agouti - related peptide (AGRP) in the arcuate nucleus [11,14]. Both NPY and AGRP stimulate food intake [14]. Chronic administration of ghrelin increases body weight [15].

Obesity actually is a major public health problem and is recognized when body mass index (BMI) is greater than 30 . Prevalence of obesity in the USA is estimated at $31 \%$ [16]. More than $15 \%$ of the population in European countries such as England, Germany and Poland are obese [17]. Obesity is strongly associated with comorbidities such as diabetes, hypertension, coronary artery disease and sleep apnea. Bariatric surgery is recommended for patients with $\mathrm{BMI} \geq 40$ or BMI $\geq 35$ with associated comorbidities and it efficiently induces substantial weight loss and improves obesity - related diseases [18]. The most popular bariatric procedure in the USA is Roux - Y Gastric Bypass (RYGB) but in Europe the most often Laparoscopic Adjustable Gastric Banding is performed $[19,20]$.

The aim of our study was evaluation of the activity of gastric X/A-like cells in obese patients before and after LAGB and RYGB procedures.

\section{Material and methods}

Patients and surgical procedures. The study was performed among morbidly obese patients who underwent RYGB or LAGB in the $1^{\text {st }}$ Department of General and Endocrinological Surgery at the Medical University of Białystok between January and December of 2007. The indications for surgery included $\mathrm{BMI} \geq 40$ or $\mathrm{BMI} \geq 35$ with associated comorbidities. Patients with psychiatric disorders or older than 65 years old were excluded.

Eighteen patients took part in the study. There were 14 females and 4 males in mean age $45.4 \pm 11.46$ years old with mean body weight $140.6 \pm 23.5 \mathrm{~kg}$ and mean BMI $50.5 \pm 7.57$. LAGB was performed in 7 patients ( 7 females) at the mean age $34 \pm 9.67$ with mean body weight $127.67 \pm 4.9 \mathrm{~kg}$ and mean BMI 44.3 \pm 3.7 . RYGB was performed in 11 patients ( 7 females and 4 males) at the mean age $50.9 \pm 7.8$ with mean body weight $147.1 \pm 26.6$ and mean BMI $54.5 \pm 6.72$. The control group of patients consisted of 7 patients admitted because of chronic cholecystitis. There were 6 females and 1 male in mean age $43 \pm 18$ years old with mean body weight $64.7 \pm 10.88 \mathrm{~kg}$ and mean BMI $24.9 \pm 4.41$.

RYGB was performed in open method and it consists of 3 basic steps. Each operation started with the creation of a gastric pouch followed by gastrojejunostomy. Jejunojejunostomy about $100 \mathrm{~cm}$ down the Roux limb was made at the end. Gastrojejunostomy was performed with circular stapler and circular specimen of stomach was collected for immunocytochemical research.

LAGB is purely restrictive bariatric method. The procedure needs special silicone band containing balloon connected with the drain to the port. LAGB consists of dissection of the proximal stomach and band placement. The port gives possibility for band diameter regulation.

Measurement of ghrelin plasma concentration. Peripheral blood was taken from each morbidly obese patient before and first day, seventh day, 1 month and 3 months after surgery. Blood was collected into polypropylene tubes without anticoagulant. Within 2 hours of collection, the blood samples were centrifuged $(4000 \times$ for $20 \mathrm{~min}$ ). The serum was removed using sterile technique and immediately frozen at $-30^{\circ} \mathrm{C}$ until a consequent analysis. Ghrelin level was determined by the double - antibody radioimmunoassay technique. The protocol for radioimmunoassay kit is accessible on the web site: www.phoenixpeptide.com.

The immunocytochemical study. The circular specimens of stomach were taken from circular stapler after gastrojejunostomy during RYGB. Then specimens were fixed in Bouin's fluid for one day at $4^{\circ} \mathrm{C}$. After thorough washing in $0.1 \mathrm{M}$ phosphate buffer $(\mathrm{pH}=7.4)$ at $4^{\circ} \mathrm{C}$, the tissues were routinely embedded in paraffin, and $5-\mu \mathrm{m}-$ thick sections were cut. For blocking of the endogenous peroxidase activity Peroxidase Blocking Reagent (Dako Poland) were used over 10 minutes. In these studies a specific antibody against ghrelin (Phoenix) were used. After washing with dis-

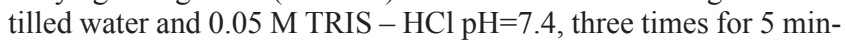
utes, the sections were incubated with the antibody for 1 hour at room temperature. Then, sections were washed three times in TRIS buffer. Subsequently, the EnVision method was applied, according to the protocol for identification of the immunocytochemical reaction [21]. The sections were counterstained with Mayer's haematoxylin. In the negative control, the specific antibodies were omitted in the staining procedure. Positive controls were done for specific tissue recommended by the producer. The histological preparations were subjected to analysis, using Olympus $\mathrm{B} \times 50$ microscope.

Image analysis. To quantify immunoreactivity of the examined marker, computerized image analysis were performed. Images were captured via video link to an Olympus BX50 microscope at 20 objective magnification, so the tissue fully occupied each field, and was scanned by the computer. Pictures were adjusted for optimal contrast, fixed at the same brightness levels, and saved in a buffering system. Staining was analyzed using Olympus Cell D image analysis computer system as described in details by Postek et al. [22]. The average optical density was analyzed for cells expressing ghrelin in both, experimental and control specimens. The average optical density is the method measured values range from 0 to 255 where 0 means black and 255 white color.

Ethical issues. The study protocol was approved by the Ethics Committee Medical University of Białystok and written informed consent was obtained from each participant. 
Table 1. The means ghrelin plasma concentrations (pg/ml). Values are means $\pm \mathrm{SD},{ }^{*} \mathrm{p}<0.05,{ }^{* *} \mathrm{p}<0.001$ vs before surgery (student's test).

\begin{tabular}{|c|c|c|c|c|c|}
\hline $\begin{array}{c}\text { Type of } \\
\text { procedure }\end{array}$ & $\begin{array}{c}\text { Concentration before } \\
\text { surgery }\end{array}$ & $\begin{array}{c}1^{\text {st }} \text { day after } \\
\text { surgery }\end{array}$ & $\begin{array}{c}7^{\text {th }} \text { day after } \\
\text { surgery }\end{array}$ & $\begin{array}{c}1 \text { month after } \\
\text { surgery }\end{array}$ & $\begin{array}{c}3 \text { months after } \\
\text { surgery }\end{array}$ \\
\hline LAGB & $94.2 \pm 52.9$ & $42.42^{*} \pm 12.3$ & $87.17 \pm 24.4$ & $79.55 \pm 21.8$ & $140.6^{*} \pm 49.2$ \\
\hline RYGB & $81.2 \pm 21.9$ & $37.4^{* *} \pm 16.4$ & $66.6 \pm 31.8$ & $92.8 \pm 38.9$ & $80.2 \pm 27.6$ \\
\hline
\end{tabular}

Statistical analysis. All values were given as mean \pm SD. The Mann-Whitney test was used for testing the differences between both groups in the intensity of immunocytochemical reactions. The Student-T test was used for the evaluation of the differences between groups in ghrelin plasma concentrations and in decrease of weight. The value $\mathrm{p}<0.05$ was considered to be significant.

\section{Results}

The mean BMI one month after RYGB was $46.89,3$ months $-42.91,6$ months -40.52 and 12 months 34.67 (Fig. 1). The mean excess weight loss (EWL) after RYGB was $21.26 \%$ at the end of first month, $38.01 \%$-3th month, $47.04 \%-6^{\text {th }}$ month and $66.36 \%-$ 12 month (Fig. 3). The mean BMI 1 month after LAGB was $40.36,3$ months $-35.95,6$ months -30.84 and 12 months -26.85 (Fig. 2). The mean EWL after LAGB was $22.28 \%$ at the end of first month, $39.48 \%$ - 3th month, $44.84 \%-6^{\text {th }}$ month, and $55.14 \%-12$ month (Fig. 3).

The mean ghrelin concentration before surgery in both LAGB and RYGB treated groups was similar and correspondingly $94.2 \pm 52.9$ and $81.2 \pm 21.9 \mathrm{pg} / \mathrm{ml}$. In both groups substantial decrease of ghrelin plasma concentration was observed at first day after surgery (Fig 4,5). The mean ghrelin concentration first day, seventh day, 1 month after LAGB was correspondingly $42.42 \pm 12.3,87.17 \pm 24.4,79.55 \pm 21.8$ and after RYGB $-37.4 \pm 16.4,66.6 \pm 31.8,92.8 \pm 38$.9. The significant increase of ghrelin plasma concentration (mean values $140.6 \pm 49.2 \mathrm{pg} / \mathrm{ml}) 3$ months after LAGB as compared to the mean value $(80.2 \pm 27.6 \mathrm{pg} / \mathrm{ml}) 3$ months after RYGB was observed. The mean ghrelin concentration in the control group was $141.6 \pm 21.5$ $\mathrm{pg} / \mathrm{ml}$. The means results of ghrelin plasma concentrations after LAGB and RYGB are presented in Table 1.

\section{Results of histological study}

Ghrelin immunoreactive (Ghr-IR) cells were distributed predominantly as single cells, locally in varying number in the deep zone of the gastric mucosa (Fig. 6). Ghr-IR cells were most abundant in lower parts of gastric proper glands, while in the neck zone of the glands they were observed sporadically, both in the control and in the experimental group. These cells were usually round or oval, sometimes spindle-shaped, seldom irregular with short processes. Their nuclei were usually large, round structures that occupy the central portions of cells. While in the X/A like cells of morbidly obese GH-immunoreactivity appeared as a very strong reaction (Fig. 7), the GH-immunoreactivity of X/A like cells not-obese patients was weaker (Fig. 8). The average optical density of immunocytochemical gastric mucosa reaction for ghrelin, evaluated by Olympus Soft program, was significantly decreased in morbidly obese in comparison to the control not-obese patients (Fig. 9).

\section{Discussion}

The main finding of the present study is the hypoactivity of gastric X/A-like cells in obese patients in comparison to the control group, confirmed by immunohistochemical study and ghrelin plasma concentration. We observed very strong immunohistochemical reactions of gastric X/A-like cells, accompanied by lower ghrelin plasma concentration in comparison to the control group. The ghrelin plasma level was significantly decrease 1 day after LAGB and RYGB procedures, but in the next points of our observations (7 days, 1 and 3 months after surgery) the plasma concentration of investigated hormone started to increase to the similar level as we noted before surgery. We haven't noted any statistical differences in ghrelin plasma level between two investigated groups after 1 day, 7 days and 1 month, but significantly lower ghrelin plasma concentration 3 months after RYGB in comparison to the LAGB procedure.

The regulation of ghrelin synthesis and secretion in physiological and pathological condition is still unknown and controversial. Total fasting ghrelin levels are decreased in human obesity, which might represent a compensatory response to a sustained positive energy balance [15]. Among obese otherwise healthy adults plasma ghrelin concentrations are lower in the most of insulin resistant subjects relative to equally obese individuals with relatively higher insulin sensitivity [23]. The only exception to the negative association between body mass index and ghrelin secretion is the Prader-Willi syndrome where obesity is surprisingly associated with ghrelin hypersecretion [24]. The mechanism of down-regulated ghrelin secretion in obese patients is still unknown [24]. In animals, ghrelin is secreted in a pulsatile manner without strict correlation with $\mathrm{GH}$ levels but in association with food intake episodes $[13,15]$. In humans, ghrelin secretion undergoes marked variations throughout the day, with peaks preceding food intake, suggesting that the latter 


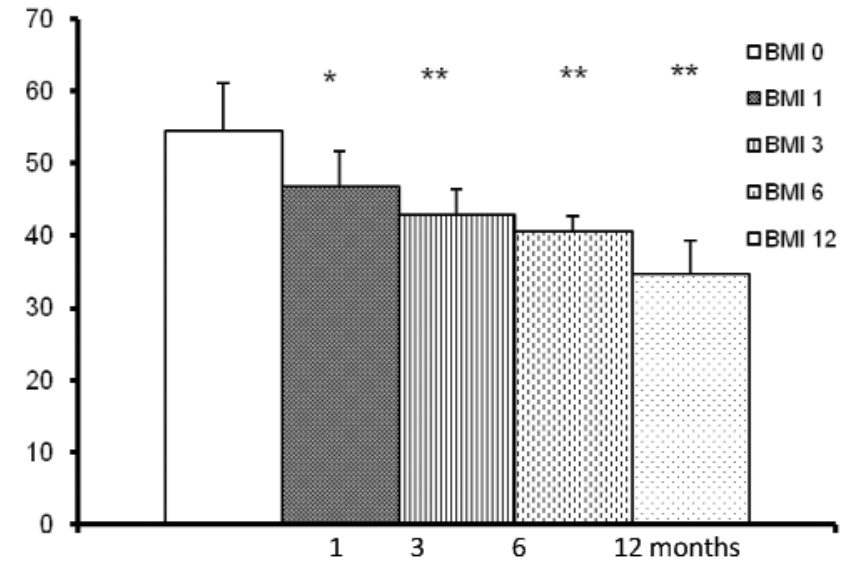

Fig. 1. The decrease of BMI after RYGB. Values are means $\pm S D$, ${ }^{*} \mathrm{p}<0.05,{ }^{* *} \mathrm{p}<0.001$ vs BMI before surgery (student's test).

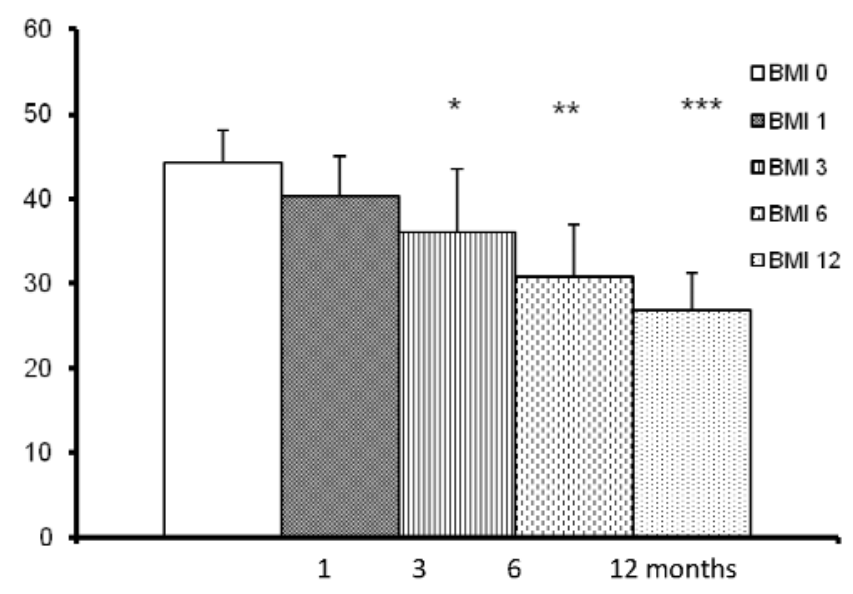

Fig. 2. The decrease of BMI after LAGB. Values are means $\pm S D$, ${ }^{*} \mathrm{p}<0.05,{ }^{* *} \mathrm{p}<0.001,{ }^{* * *} \mathrm{p}<0.0001$ vs BMI before surgery (Student's test).

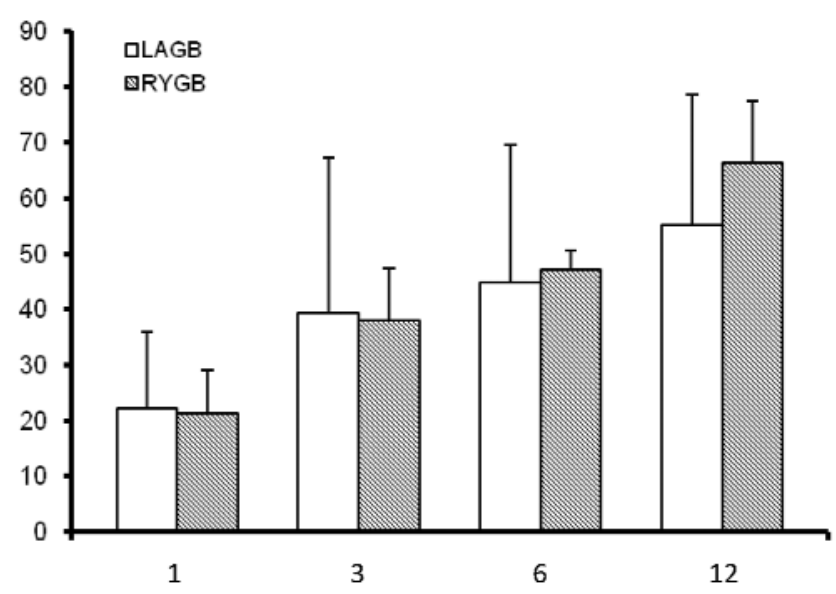

Fig. 3. EWL (\%) during 12 months follow up after RYGB and LAGB.

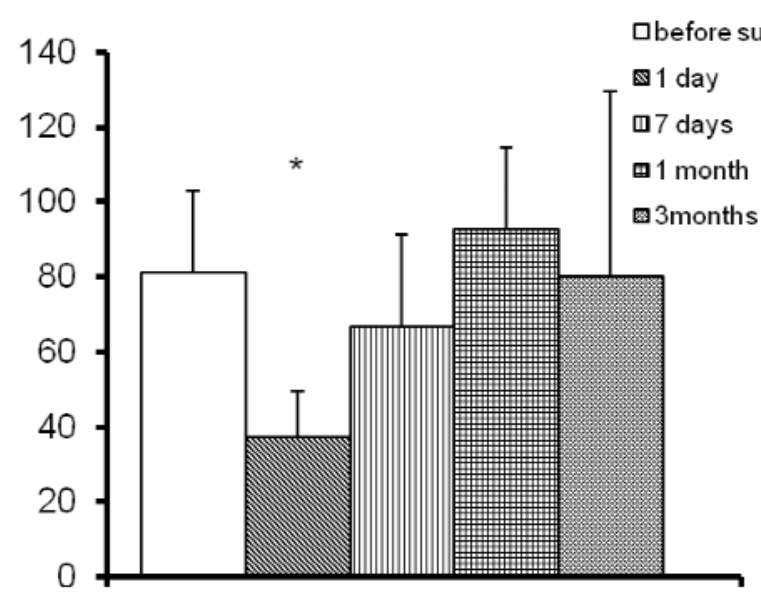

Fig. 4. The ghrelin plasma concentration before and after RYGB. Values are means $\pm \mathrm{SD},{ }^{*} \mathrm{p}<0.05$ vs 1 day after surgery (student's test).

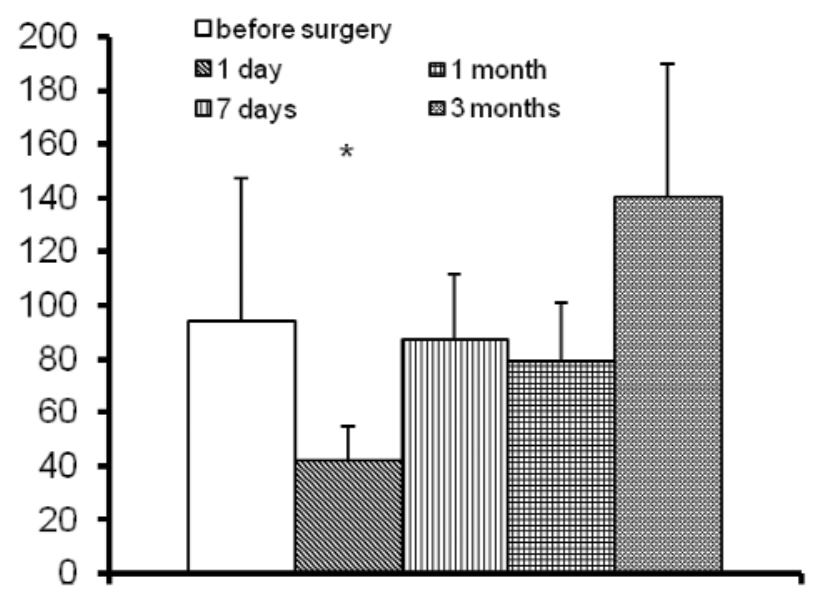

Fig. 5. The ghrelin plasma concentration before and after LAGB. Values are means $\pm \mathrm{SD},{ }^{*} \mathrm{p}<0.05$ vs 1 day after surgery (student's test).

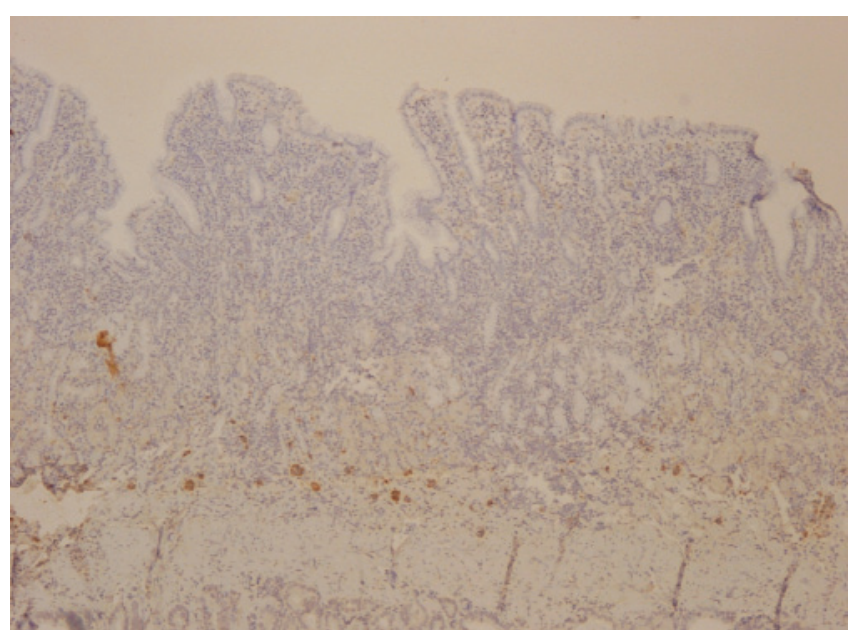

Fig. 6. Light micrograph of gastric mucosa of a control patient. Positive immunohistochemical reaction for ghrelin is observed in $\mathrm{X} / \mathrm{A}$ like cells in the deep zone of the gastric mucosa (original magnification $\times 100$ ). 


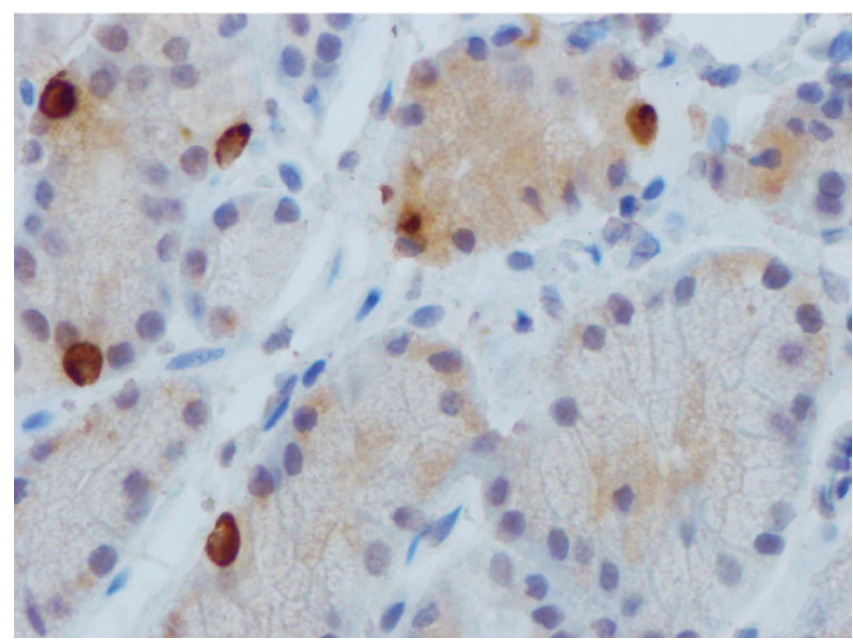

Fig. 7. Light micrograph of gastric mucosa of obese patient. Positive immunohistochemical reaction for ghrelin is observed in X/A like cells (original magnification $\times 400$ ).



Fig. 8. Light micrograph of gastric mucosa of a control patient. Positive immunohistochemical reaction for ghrelin is observed in $\mathrm{X} / \mathrm{A}$ like cells (original magnification $\times 400$ ).

is triggered by ghrelin discharge [24]. Circulating ghrelin levels are negatively associated with body mass index; ghrelin secretion is increased in anorexia and cachexia, reduced in obesity and normalized by recovery of ideal body weight [24].

In our present study hypoactivity of gastric ghrelin-positive cells, confirmed by strong immunoreactivity and lower ghrelin plasma concentration in comparison to the control group, may be a consequence of increasing secretion of insulin as a result of positive energy balance in obese. The correlation of body mass index (BMI) with risk for type 2 diabetes mellitus is positive and the association between obesity and insulin resistance is largely due to changes in the function of adipose tissue, specifically, increased release of free fatty acids and abnormalities in adipokine secretion [25]. The properties of visceral adipose tissue may provide cause these dysfunctions to become magnified

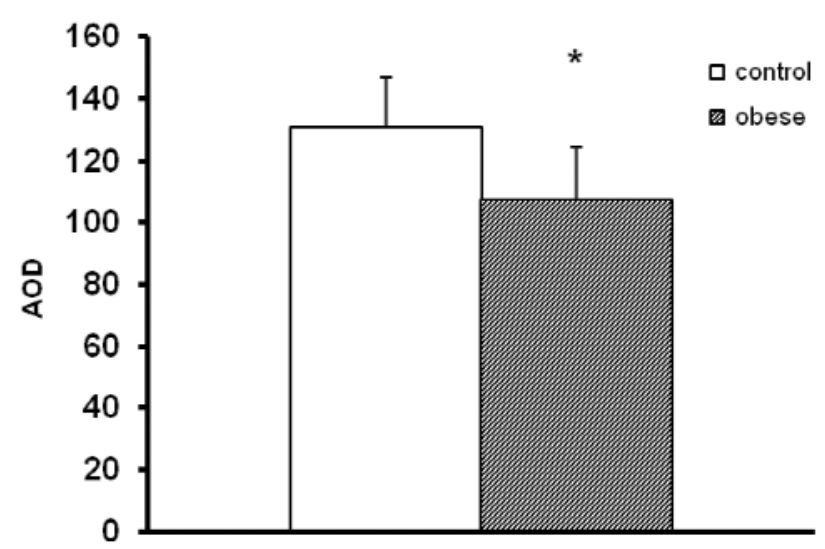

Fig. 9. Average optical density of immunohistochemical staining for ghrelin in X/A-like cells. Values are means $\pm \mathrm{SD},{ }^{*} \mathrm{p}<0.05$ vs control (Mann-Whitney test).

[25]. Saad et al [26] in 2002 reported that hyperinsulinemia reduced plasma ghrelin concentration. Ghrelin secretion is decreased by either intravenous or oral glucose load as well as during euglycaemic-hyperinsulinaemic clamp and even after insulin-induced hypoglycaemia [26]. The inhibitory influence of overexposure to insulin on ghrelin secretion is consistent with the strong negative association between ghrelin and insulin levels that had been predicted by the negative correlation between ghrelin levels and body mass index, however, it is still unclear whether insulin and glucose per se play a direct inhibitory role in ghrelin secretion [26]. Jyh-Ming Liou et al [27] demonstrated that in nondiabetic obese patients the insulin and glucose levels were higher in comparison to healthy subjects.

Another hypothesis trying to explain perturbation of ghrelin secretion after bariatric surgery is denervation of autonomic nervous system regulating the activity of ghrelin-producing tissue in the foregut. It was demonstrate that vagotomy in rats eliminates the increase of ghrelin that normally accompanies weight loss, as is often observed after RYGB [28]. Severing of vagal input to the foregut is accomplished variably by different surgeons performing RYGB, so this hypothesis could explain some of the heterogeneity in data pertaining to the effect of this operation on ghrelin levels [29]. A neural mechanism might also explain the very rapid decline in ghrelin levels observed within 24 hours of the operation [30]. In our present study we also observed rapid decrease of ghrelin plasma concentration one day after RYGB procedure.

The role of cholinergic nervous system in the regulation of ghrelin secretion was investigated by Maier et al [31]. They examined the effects of the cholinergic antagonist atropine on ghrelin, peptide YY (PYY), glucose, and insulin under basal conditions and after meal ingestion in lean and obese subjects [31]. The study 
showed that, atropine led to a decrease in ghrelin concentrations comparable and nonadditive with breakfast ingestion and a significant decrease in both basal and meal-induced PYY concentrations in lean individuals [31]. In obese subjects, atropine did not significantly change ghrelin or PYY concentrations, whereas it induced a comparable meal-induced glucose concentrations in the two study groups [31]. Only lean subjects experienced sustained feelings of satiety after breakfast. Maier concluded that impaired cholinergic regulation of the postprandial drop in ghrelin concentrations and rise in PYY concentrations might be part of the deregulated food intake in obese subjects [31].

LAGB is a purely restrictive bariatric procedure and most studies showed that ghrelin levels increase after this operation [32]. LAGB is less invasive method than RYGB, mainly because it is laparoscopic procedure and preserves stomach in its anatomic site. Ghrelin level increases after LAGB in response to the energy restriction [32]. In our study we observed similar tendency in ghrelin plasma concentration.

Efficiency of RYGB and LAGB procedures was estimated by EWL- excess weight loss. In each point of our observation after surgery we observed significant reduction of weight (BMI and EWL), but the EWL was not significantly higher in patients 1 year after RYGB in comparison to the LAGB procedure. According to many authors RYGB results in $65 \%$ to $69 \%$ EWL at first year $[33,34]$. We have similar result in our study. LAGB is restrictive procedure, needs patient's co-operation in treatment process and causes about 51\% EWL at first year [35,36]. Patient should avoid sweets and high caloric drinks for better effects after this operation. We have noticed comparable value of EWL to other studies one year after LAGB.

The greater weight loss after RYGB compared with LAGB observed by another authors may be an result of more effective influence on appetite reduction after RYGB [37,38]. The greater efficacy of RYGB is most often hypothesized to result from malabsorption and dumping syndrome [39]. Impairment of ghrelin secretion might account in part for the loss of hunger after RYGB [40]. The most of studies show decrease of ghrelin plasma concentration after RYGB, but some prospective studies revealed no change in ghrelin levels after RYGB, despite the massive weight loss [4043].Those heterogeneity in results probably are because of subtle differences in surgical technique. The position of the staple line partitioning the stomach in RYGB could be a critical determinant of weight loss. Placing this partition even slightly too far to the left would include part of the fundus (the richest source of ghrelin) in the upper gastric pouch, thus failing to exclude the fundus from contact with food and undermining override inhibition [39].

\section{Conclusions}

In conclusion, our study indicated hypoactivity of gastric X/A-like cells in obese patients confirmed by immunohistochemical study and ghrelin plasma concentration. Moreover LAGB procedure induced increase of ghrelin plasma level while RYGB procedure induced decrease of this hormone. The mechanism of ghrelin secretion disturbance after RYGB is not clear.

Acknowledgements: This study was supported by UMB grants no 3-40886L and 3-40765L

\section{References}

[1] Murray CD, Kamm MA, Bloom SR, Emmanuel AV. Ghrelin for the Gastroenterologist: History and Potential. Gastroenterology. 2003;125:1492-1502.

[2] Dimaraki EV, Jaffe CA. Role of endogenous ghrelin in growth hormone secretion, appetite regulation and metabolism. Rev Endocr Metab Disord. 2006;7:237-249.

[ 3] Kojima M, Hosoda H, Date Y, Nakazato M, Matsuo H, Kongawa K. Ghrelin is a growth-hormone-releasing acylated peptide from stomach. Nature. 1999;402:656-660.

[ 4] Date Y, Kojima M, Hosoda H et al. Ghrelin, a novel growth hormone-releasing acylated peptide, is synthesized in a distinct endocrine cell type in the gastrointestinal tracts of rats and humans. Endocrinology. 2000;141:4255-4261.

[ 5] Solcia E, Capella C, Vassallo G, Buffa R. Endocrine cells of the gastric mucosa. International Review of Cytology. $1975 ; 42: 223-286$

[6] Gnanapavan S, Kola B, Bustin SA et al. The tissue distribution of the mRNA of ghrelin and subtypes of its receptor, GHS-R, in humans. J Clin Endocrinol Metab. 2002;87:298891.

[ 7] Ariyasu H, Takaya K, Tagami T et al. Stomach is a major source of circulating ghrelin, and feeding state determines plasma ghrelin-like immunoreactivity levels in humans. $J$ Clin Endocrinol Metab. 2001;86:4753-8.

[ 8] Sakata I, Nakamura K, Yamazaki M et al. Ghrelin-producing cells exist as two types of cells, closed- and opened-type cells, in the rat gastrointestinal tract. Peptides 2002;23:531-6.

[ 9] Lely AJ, Tschop M, Heiman ML, Ghigo E. Biological, physiological, pathophysiological, and pharmacological aspects of ghrelin. Endocr Rev. 2004;25:426-57.

[10] Hosoda H, Kojima M, Matsuo H, Kangawa K. Ghrelin and des-acyl ghrelin: two major forms of rat ghrelin peptide in gastrointestinal tissue. Biochemistry Biophysics Research Communications. 2000;279:909-913.

[11] Ueno H, Yamaguchi H, Kangawa K, Nakazato M. Ghrelin: a gastric peptide that regulates food intake and energy homeostasis. Regulatory Peptides. 2005;126:11-19.

[12] Kojima M, Kangawa K. Ghrelin, an orexigenic signaling molecule from the gastrointestinal tract. Current Opinion in Pharmacology. 2002;2:665-668.

[13] Tschop M, Smiley DL, Heiman ML. Ghrelin induces adiposity in rodents. Nature. 2000;407:908-913.

[14] Kojima M, Hosoda H, Kangawa K. Ghrelin, a novel growthhormone-releasing and appetite-stimulating peptide from stomach. Best Practice \& Research Clinical Endocrinology \& Metabolism. 2004;18:517-530.

[15] Cummings DE. Ghrelin and the short- and long-term regulation of appetite and body weight. Physiology \& Behavior. 2006;89:71-84. 
[16] Hedley AA, Ogden CL, Johnson CL et al. Prevalence of overweight and obesity among US children, adolescents, and adults, 1999-2002. JAMA. 2004;291:2847-2850.

[17] Östman J, Britton M, Jonsson E. Treating and preventing obesity: an evidence-based review. The Swedish Council of Technology Assessment in Health Care (SBU). Weinheim, Wiley-VCH; 2004.

[18] Pannala R, Kidd M, Modlin IM. Surgery for Obesity: Panacea or Pandora's Box? Dig Surg. 2006;23:1-11.

[19] Schauer PR, Ikramudin S, Gourash W, et al. Outcomes after laparoscopic Roux-en-Y gastric bypass for morbid obesity. Ann Surg. 2000;232:515-29.

[20] Leffler E, Gustavs son S, Karlson BM. Time trends in obesity surgery 1987 through 1996 in Sweden: a population-based study. Obes Surg. 2000;10:543-8

[21] Herman GE, Elfont EA. The taming of immunohistochemistry: the new era of quality control. Biotech Histochem. 1991;66:194-199.

[22] Postek A, Andronowska T, Doboszyńska T, Niewęgłowski H, Jankowska K. VEGF, VEGFR-1 and VEGFR-2 immunoreactivity in the porcine arteries of vascular subovarian plexus (VS P) during the estrous cycle. Folia Histochem Cytobiol. 2006;44:17-23.

[23] McLaughlin T, Abbasi F, Lamendola C, Frayo RS, Cummings DE. Plasma ghrelin concentrations are decreased in insulinresistant obese adults relative to equally obese insulin-sensitive controls. J Clin Endocrinol Metab. 2004;89:1630-1635.

[24] Leite-Moreira AF, Soares JB. Physiological, pathological and potential therapeutic roles of ghrelin. Drug Discovery Today. 2007; 12:276-288.

[25] Westphal SA. Obesity, abdominal obesity, and insulin resistance. Clin Cornerstone. 2008;9:23-31.

[26] Saad MF, Bernaba B, Hwu CM et al. Insulin regulates plasma ghrelin concentration. J Clin Endo crinol Metab. 2002;87:3997-4000.

[27] JM Liou, JT Lin, WJ Lee et al. The Serial Changes of Ghrelin and Leptin Levels and Their Relations to Weight Loss After Laparoscopic Minigastric Bypass Surgery. Obes Surg. 2008;18:84-89.

[28] Williams DL, Grill HJ, Cummings DE et al. Vagotomy dissociates short- and long-term controls of circulating ghrelin. Endocrinology. 2003;144:5184-7.

[29] Cummings DE, Shannon MH. Ghrelin and gastric bypass: Is there a hormonal contribution to surgical weight loss? J Clin Endocrinol Metab. 2003;88:2999-3002.

[30] Fruhbeck G, Caballero AD, Gil MJ. Fundus functionality and ghrelin concentrations after bariatric surgery. New Engl $J$ Med. 2004;350:308-9.
[31] Maier C, Riedl M, Vila G et al. Cholinergic regulation of ghrelin and peptide YY release may be impaired in obesity. Diabetes. 2008;57:2332-40.

[32] Lee H, Te C, Koshy S, Teixeira JA, Pi-Sunyer XF, Laferrere B. Does ghrelin really matter after bariatric surgery? Surgery for Obesity and Related Diseases. 2006;2:538-548.

[33] Pories WJ, MacDonald Jr. KG, Morgan EJ et al. Surgical treatment of obesity and its effect on diabetes: 10-y followup. Am J Clin Nutr 1992; 55(2 supplement): 582-585.

[34] Sugerman HJ, Kellum JM, Engle KM et al. Gastric bypass for treating severe obesity. The American Journal of Clinical Nutrition. 55(2 supplement): 560-66

[35] O'Brian P, Brown W, Smith A et al. Prospective study of a laparoscopically placed, adjustable gastric band in the treatment of morbid obesity. Br J Surg. 1999;85:113-118.

[36] Stieger R, Thurnheer M, Lange J. Morbid obesity: 130 consecutive patients with laparoscopic gastric banding. Schweiz Med Wochenschr. 128:1239.

[37] Buchwald H, Avidor Y, Braunwald E et al. Bariatric surgery: A systematic review and meta-analysis. JAMA. 2004;292:1724 -37.

[38] Howard L, Malone M, Michalek A et al. Gastric bypass and vertical banded gastroplasty: A prospective randomized comparison and 5-year follow-up. Obes Surg. 1995;5:55-60.

[39] Cummings DE, Overduin J, Shannon MH, Foster-Schubert KE. Hormonal mechanisms of weight loss and diabetes resolution after bariatric surgery. Surgery for Obesity and Related Diseases. 2005;1:358-368.

[40] Geloneze B, Tambascia MA, Pilla VF et al. Ghrelin, a gutbrain hormone: Effect of gastric bypass surgery. Obes Surg. 2003; 13:17-22.

[41] Lin E, Gletsu N, Fugate K et al. The effects of gastric surgery on systemic ghrelin levels in the morbidly obese. Arch Surg. 2004;139:780-4.

[42] Stoeckli R, Chanda R, Langer I et al. Changes of body weight and plasma ghrelin levels after gastric banding and gastric bypass. Obes Res. 2004;12:346-50.

[43] Copeland P, Davis P, Kaplan L. Weight loss after gastric bypass is associated with decreased plasma gastric inhibitory polypeptide without a significant change in circulating ghrelin. Obes Res. 2003;11(suppl):A17.

Submitted: 2 January, 2009 Accepted after reviews: 13 March, 2009 